\section{EDUCAÇÃO AMBIENTAL E POLÍTICAS PÚBLICAS: FOCO DE INTERVENÇÃO NO SISTEMA EDUCACIONAL}

Simone Teles da Silva Santo

Avelar Luíz Bastos Mutim

\section{ENVIRONMENTAL \\ EDUCATION AND PUBLIC POLICIES: FOCUS OF INTERVENTION INTHE EDUCATIONAL SYSTEM}

\section{Resumo}

Neste artigo contextualizamos a formulação das políticas públicas no âmbito educativo, discorremos sobre a educação ambiental que se faz urgente e necessária nos dias atuais, para depois indicarmos que as políticas públicas, não são geradas e nem legitimadas pelo cidadão comum pois este mantém-se à margem da esfera da formulação, implementação e avaliação nas diferentes etapas da tomada de decisão. $\mathrm{O}$ artigo traz uma abordagem dos diferentes imbricamentos que envolvem o desenvolvimento das políticas educacionais. Pretendemos analisar as relações entre educação e as políticas públicas vigentes, visando o reconhecimento das questões que levam a não efetivação de políticas que já estão promulgadas, mas não efetivadas, diante do cenário complexo que se apresenta as questões educacionais que envolve a inserção da educação ambiental nos diferentes espaços da sociedade. Argumentamos que a participação social atualmente tem caráter emergencial. Acreditamos que as informações e os conhecimentos adquiridos por meio da Educação Ambiental e outras práticas sociais estão transformando os costumes e criando atitudes que melhoram as ações vinculadas aos programas sociais.

Palavras-chave: Educação Ambiental. Políticas Ambientais. Políticas Públicas. Sistema Educacional.

\section{Abstract}

In this article we contextualize the formulation of public policies in the educational field, we discuss the environmental education that is urgent and necessary nowadays, to later indicate that public policies are not generated nor legitimized by the common citizen because it remains at the scope of formulation, implementation and evaluation at the different stages of decision making. The article presents an approach to the different imbrications that involve the development of educational policies. We intend to analyze the relationship between education and current public policies, aiming at the recognition of the issues that lead to the non-implementation of policies that are already promulgated, but not implemented, given the complex scenario that presents the educational issues that involve the insertion of environmental education. in the different spaces of society. We argue that social participation is currently emergency. We believe that information and knowledge acquired through Environmental Education and other social practices are transforming customs and creating attitudes that improve actions linked to social programs.

Keywords: Environmental Education. Environmental Policies. Public policy. Educational system. 


\section{EDUCACIÓNAMBIENTALY POLÍTICAS PÚBLICAS: FOCO DE INTERVENCIÓN EN EL SISTEMA EDUCATIVO.}

\section{Resumen:}

En este artículo contextualizamos la formulación de políticas públicas en el campo educativo, discutimos la educación ambiental que es urgente y necesaria hoy en día, para luego indicar que las políticas públicas no son generadas ni legitimadas por el ciudadano común porque permanece en el alcance de la formulación, implementación y evaluación en las diferentes etapas de la toma de decisiones. El artículo presenta un enfoque de las diferentes imbricaciones que implican el desarrollo de políticas educativas. Pretendemos analizar la relación entre la educación y las políticas públicas actuales, con el objetivo de reconocer los problemas que conducen a la no implementación de políticas que ya se han promulgado, pero no implementado, dado el complejo escenario que presenta los problemas educativos que implican la inserción de la educación ambiental. en los diferentes espacios de la sociedad. Argumentamos que la participación social es actualmente una emergencia. Creemos que la información y el conocimiento adquiridos a través de la Educación Ambiental y otras prácticas sociales están transformando las costumbres y creando actitudes que mejoran las acciones vinculadas a los programas sociales.

Palabras clave: Educación ambiental. Políticas ambientales. Políticas públicas. Sistema educativo.

\section{Introdução}

São poucos os estudos que relacionam as temáticas de políticas públicas com os esforços para consolidar a Educação Ambiental como prática social. Daí a necessidade de fazer um levantamento das dissertações e teses focando nos descritores Políticas Públicas e Educação Ambiental de modo a constatar que as pesquisas atuais já despontam, de maneira tímida, como instrumentos capazes de diagnosticar um certo imbricamento das políticas de Educação Ambiental, principalmente no espaço escolar, como promotora de mudança de postura de como agir para utilizar e gerir o patrimônio socioambiental de modo sustentável objetivando um novo modo de viver em sociedade. Como tem sido apregoado por autores como Mutim, Carvalho, Grun, entre outros.

Nesses e em outros autores percebemos que os problemas ambientais emergem a olhos nus. A partir da atual conjuntura política observamos que o quadro ambiental que desponta no país, nos indica o quanto urge ações de políticas públicas ajustadas às necessidades de implementação de medidas para a solução dos problemas ambientais.

As instruções educativas estão diretamente interligados como problemas a serem tratados e resolvidos conjuntamente, conforme afirma pontualmente Tozoni-Reis (2008, p. 02), "a educação dos indivíduos para o uso mais equilibrado dos recursos foi apontada como uma das estratégias para solução dos problemas ambientais", já que são parte inerente ao caos que se estabeleceu nas práticas vividas e desenvolvidas no cotidiano dos seres humanos.

Nesse processo formativo, buscamos com isso compreender as políticas educativas versadas tendo como estratégia a participação efetiva da sociedade. A preocupação em discutir, em escalas maiores, as práticas exercidas para a efetividade das políticas educacionais vigentes está direcionada ao modo de utilização dos recursos naturais, isso porque, pontua-se que as ações humanas estavam levando o meio ambiente a uma deterioração aceleradamente.

Como escopo para o desenvolvimento e compreensão sobre abordagens das políticas públicas no contexto educativo, tomamos como 
ponto de discussão a trajetória dos processos implícitos na política educacional brasileira. Para tanto, procuramos analisar as relações entre Educação Ambiental e algumas políticas públicas vigentes.

Ao longo do texto travamos discussões acerca das políticas e suas conjunturas para a formulação de uma educação que estabeleça relacionamento entre a Educação Ambiental e as políticas educacionais, com vista, à intervenção para melhorias no processo educativo.

Despontando os acontecimentos da degradação do meio ambiente, trazemos o debate tomando por base as leis existentes e sua efetivação diante tamanhas consequências até os dias de hoje.

\section{Políticas públicas}

Dentro de uma perspectiva da influência pluralista, os movimentos de todas as categorias deveriam influenciar participando das tomadas de decisão na formação das políticas públicas que regem a vida em sociedade. Isso não incide por causa de controle gestionário e interesse particulares, as políticas públicas não são geradas e nem legitimadas pelo cidadão comum, que o mantém a margem da tomada de decisão na formação do cenário de construção das políticas públicas.

Poucas são as vezes em que o cidadão pode participar de ações para a formulação de projetos que visem manutenção em córregos, estradas, desperdício de água por tubulação danificada e aterros clandestinos e lixões a céu aberto. Ocorrências que são vistos cotidianamente pela comunidade, sendo que estes cidadãos dificilmente participam da descrição de uma normativa para sanar a situação, mesmo sendo o detentor das melhores opiniões e tendo conhecimento das soluções que podem resolver problemas para atender as necessidades da sociedade. Julgamos que cabe nessa esfera a ação de políticas educacionais visando melhorias na efetivação das políticas ambientais.

Vamos nos remeter a uma reflexão suscitada pelos escritos de Arendt, sobre o Agir e a condição humana em meio ao posicionamento de ações em prol da sociedade, como nos relata Carvalho e Sampaio, a Ação é a expressão mais nobre da condição humana. O ser humano se define por seu Agir, entre os outros humanos, influindo no mundo que o cerca. Esta capacidade de Agir, em meio à diversidade de idéias e posições é a base da convivência democrática e do exercício da cidadania. Só aí, na pluralidade e na diversidade, é possível desfrutar da liberdade de criar algo novo. Desta forma, o Agir humano é o campo próprio da educação, enquanto prática social e política que pretende transformar a realidade. (CARVALHO e SAMPAIO: 2006, p.195).

Desse modo, os fazedores de política elaboram os planos, estabelecem as prioridades, definindo ações direcionadas para o público que não participou da tomada de iniciativa e nem ao menos participou de alguma forma da formulação. Assim,

O processo de formulação de política pública é aquele através do qual os governos traduzem seus propósitos em programas e ações, que produzirão resultados ou as mudanças desejadas no mundo real. Cabe aos analistas e pesquisadores das políticas públicas compreender por que e como os governos agem em determinada direção (SOUZA:2003, p. 05).

Para formulação de uma política tem que se constatar problemas para que se projete apontamentos visando possíveis soluções, de modo que, a política esteja baseada em teorias as quais determinam causa, efeito, soluções e resultados. Sendo, no entanto, compreendida como processo para a implantação de medidas. A proposta de medidas em meio ao que se apresenta como articulação para a tomada de decisão no ensejo que estrutura as categorias de políticas, sendo estas, políticas públicas atreladas a educação e ao meio ambiente.

Atrelado a isso, pode-se conjecturar que, a população participa da tomada de decisão de maneira invisível, pois, emerge a necessidade de implantação, mas eles não impõem, o que, e como deve ser desferida a mudança. Quando Carvalho e Sampaio faz a reflexão sobre os escritos de Arendt, nos convida a participar de seu entendimento de Ação humana e de política, quando descreve que,

Porém, se o homem é um ser político, com o poder da fala, do discurso, durante as 
guerras e revoluções este poder é aniquilado: tudo e todos são silenciados. Em função do silêncio que é inerente à violência, isto é, do fato de que o discurso é impotente quando confrontado com a violência, ela é um fenômeno marginal no domínio da política. (CARVALHO e SAMPAIO, 2006, p. 196).

As políticas públicas educacionais mediante o que concerne alguns autores, são efetivadas a partir das necessidades educativas, ensejadas pela sociedade, que por meio de pedidos ressaltam seus anseios e necessidades de implementação de melhorias no processo educativo e, neste processo, o desenvolvimento da Educação Ambiental. E em busca de prática e ações transformadoras recorrem aos gestores Federais, Estaduais e Municipais.

Segundo Ortega e Peloggia, (2015) quando apresentam teorias de Álvaro Vieira pinto e Paulo Freire no texto sobre campos filosóficos da ciência e da educação, 'problemas filosóficos da pesquisa cientifica', remete ao "posicionamento de Pinto sobre a concepção do conhecimento e teoria filosófica e ideológica, enfatizando que ambos veem a educação como aportes estruturantes e reflexões parecidas. Assim descrevem "é inexato dizer que são as leis cientificas que regem os fenômenos, mas sim que são os próprios fenômenos que, por via da reflexão logica, exprimem em forma de proposições legais a unidade dos processos que os determinam" (VIEIRA PINTO, 1979, p.76 Apud ORTEGA E PELOGGIA, 2015, p. 10). O meio ambiente não é algo estático, fenômenos ambientais hão de surgir, com mais força quando há a intervenção das ações humanas sendo que essas precisam ter caráter preventivo ou corretivo dos inevitáveis impactos causados.

\section{Políticas públicas de educação ambiental}

O cenário das políticas de Educação Ambiental está aflorado e emerge com força, diante a tantas catástrofes vivenciadas na contemporaneidade. Como esclarece Mutim (1993, p. 65) "[...] para que a educação possa se revestir do caráter transdisciplinar imposto pela problemática ambiental, é necessário a construção de novas metodologias que atendam a essa integração do conhecimento". Partindo da perspectiva de que as políticas públicas de Educação Ambiental se enraizaram pelo fato de que o panorama de proteção ambiental necessitava de urgência, notase nessa visão a necessidade de melhorias no que se refere a efetivação das políticas, fiscalização e direcionamento de ações.

A Lei $n^{\circ}$ 9. 795 que instituiu a Política Nacional de Educação Ambiental -EA diz no artigo $1^{\circ}$

\begin{abstract}
entende-se por Educação Ambiental os processos por meio dos quais o individuo e a coletividade constroem valores sociais, conhecimentos, habilidades, atitudes e competências voltadas para a conservação do meio ambiente bem de uso comum do povo, essencial à sadia qualidade de vida $\mathrm{e}$ sua sustentabilidade (BRASIL, 1995, p. 01).
\end{abstract}

$\mathrm{O}$ conceito de "conservação do meio ambiente bem de uso comum", nos remete a interdisciplinaridade para o desenvolvimento de Educação Ambiental com características coletivas voltadas ao conjunto da sociedade visto que essas podem desvelar as tecnologias sociais e o conhecimento tendo em vista construir alternativas a partir de atos que envolvem as relações entre o Estado e a Sociedade.

O Art. 23 cap. VII da Política Estadual de Meio Ambiente da Bahia, remete e corrobora com a política Nacional, apresentando o seguinte, "Educação Ambiental nas políticas públicas como inserção de políticas educativas nos processos de planejamento e gestão em todas as suas etapas, fortalecendo e incentivando a participação e o controle social" (BAHIA, 2012, p. 30).

Portanto, os condicionantes também rementem ao pensar e ao fazer, devendo a Educação Ambiental, promover "articulações entre órgãos" como está descrito no Art. 25 cap. VII desta mesma Lei. Esta ressalta ainda a necessidade de transversalidade nos modos de atuação para fiscalização, licenciamento e conservação ambiental. Quando se tem informação e essa gera o conhecimento sobre cada uma delas.

Diante o que se apresenta como politica publica, tanto o ProNEA quanto o PEEA/BA chamam atenção das pessoas para refletir melhor, acerca do que já existe como política Nacional, Estadual e Municipal, todas as propostas que ressaltam a Educação Ambiental como articuladora para com 
o diálogo e a participação das pessoas no fazer dessas políticas. Atrelando Estado e Sociedade para amplificar e melhorar as ações das políticas que já estão escritas.

No entanto, outros aspectos que nos chamam a atenção na política, o entendimento que se tem sobre Educação Ambiental e a partir do disposto nos documentos legais, podemos, desse modo, pensar na totalidade no local e global, pois, ao planejar e gerir tendo como escopo as políticas públicas, estamos condicionados a refletir quem fará o que está escrito. Percebemos que a redação leva, quase sempre, para a ação do gestor ou órgãos gestores. Devemos considerar que todos somos gestores da política e que, portanto, as ações devem ser ministradas pelo coletivo e não só a um indivíduo ou uma localidade ou a um órgão gestor.

\section{A Lei 12.056/11 do Estado da Bahia expõe que}

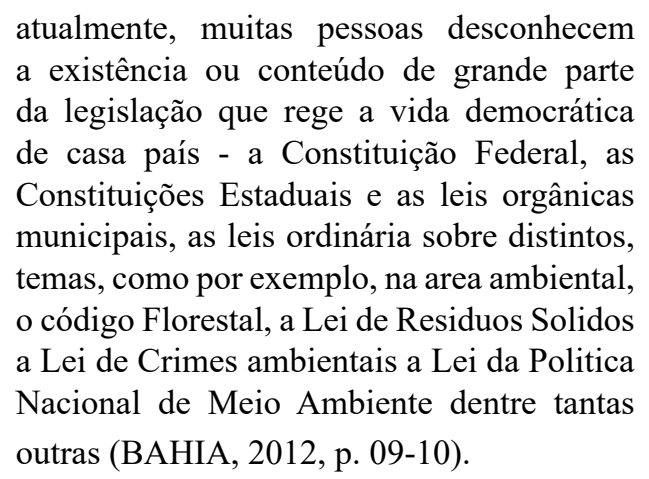

Como proposta de desenvolvimento e reflexão sobre a temática, está composto na política Estadual de Educação Ambiental os seguintes questionamentos, os quais nos remete a uma reflexão. "como propiciar conhecimento e vontade de agir, superando a alienação em relação às leis?", como promover o diálogo sobre o fazer político cotidiano como direito e dever de todos, voltado ao bem coletivo?" (BAHIA, 2012, p.10).

Diante a essa pontuação da política Estadual quando exprime o "bem coletivo", emancipação em meio a participação das pessoas nas tomadas de decisão, suas ações desferidas ao meio ambiente é que serão modificadas.

Grün (2006, p. 75) apresenta o pensamento dos críticos cartesianos e suas principais preocupações, que "são precisamente a forma como este torna a Natureza invisível".
Ressalta que,

[...] Assim se criam áreas de silêncio na educação moderna. $\mathrm{Na}$ verdade, o próprio termo "relação" pareceria totalmente errado nesse contexto, pois aí não há qualquer relação entre a Natureza e os seres humanos. A tarefa de qualquer projeto de "ética ambiental" ou "Educação Ambiental" consiste, portanto, precisamente nessa relação." (GRÜN, 2006, p.75)

Desse modo, a Educação Ambiental tornase o aporte para o processo de conhecimento da realidade ambiental, o educador torna-se o sujeito a ser propagador dessa ação educativa, assim como está exposto no Art. 03 no cap. II inciso $\mathrm{X}$, que traz para a realidade do educador, direcionamentos e atribui "a concepção dialógica como abordagem para a construção do conhecimento, mantendo uma relação horizontal entre educador e educando, com vista à transformação socioambiental" (BAHIA, 2012, p.15). Quanto aos aspectos sociais o bom senso entre as esferas políticas deve promover equilíbrio para destacar a ação humana sem que ocorra efeitos colaterais.

Carvalho (1980, p.103) diz “[...] nós não podemos ou não deveríamos tentar controlá-lo. O ambiente faz parte do mundo de nossa experiencia". Acrescenta ainda quando cita outros autores que,“desde uma antropologia da paisagem, está se apresenta como própria condição de estar no mundo, onde se entrelaçam a cultura, a natureza e o sujeito. "(LANE, 2002-HERSCH, 2003-LOW, 2006, Apud, CARVALHO, 1980, p. 104-105). No momento tecnicamente a formulação de políticas educacionais competem ao poder público que por sua vez, promulga e versa suas condições, para tal formulação, avaliando o que atina necessário e emergente para a vida da sociedade.

\section{Políticas públicas educacionais}

A Política Educacional entre tantas outras políticas vigentes no país pode ser percebida de duas maneiras distintas, na abordagem cognitiva pode ser vista sobre a ótica das crenças, ou seja, das percepções subjetivas. Mediante a abordagem científica deve ser compreendida como normativas compostas por leis, planos, programas, projetos e normas. Essas duas abordagens da política 
educacional nos fazem perceber as conexões complexas da gestão educacional transportando nossa reflexão para as intrincadas relações que englobam as estratégias e ações políticas para o desenvolvimento do lugar, das comunidades e dos territórios. Dessa forma,

\begin{abstract}
O cenário das políticas oficiais, [...], dispõe de um amplo leque de orientações e programas como, por exemplo, o Plano Nacional de Educação, Plano de Desenvolvimento da Educação, Plano de Desenvolvimento da Escola (PDE) e o Programa Dinheiro Direto na Escola (PDDE). Tal cenário está alicerçado em um arcabouço legal composto pela Constituição Federativa do Brasil, Constituição dos Estados, Leis Orgânicas Municipais e a Lei de Diretrizes e Bases da Educação Nacional (NOVAES e CARNEIRO: 1992, p. 96).
\end{abstract}

Esse tem sido o modo de compreender a política educacional que se desdobra em programas e projetos na execução de ações e processos que consolidam o fazer de políticas públicas nos meios e espaços educacionais.

No cerne dessas políticas públicas está a Educação Ambiental que deveria ser mais bem estruturada para efetivar a convivência para com o ambiente e a natureza. Assim, as políticas educacionais precisam ser levadas em conta quando pensamos na Educação Ambiental pois os processos estão intimamente relacionados visto que esta se refere a capacidade do indivíduo se relacionar melhor com o seu entorno estruturando de forma sustentável seu modo de viver. Este é, sem dúvida, também os propósitos dos diferentes programas e projetos que dão suporte ao fazer educativo seja no âmbito cognitivo de caráter subjetivo como também o normativo que se caracteriza pela objetividade prevista na gestão educacional.

As melhorias que estão por trás das iniciativas educacionais tem a ver com o desenvolvimento sustentável que atua em benefício das pessoas, da saúde e do bem-estar de todos incluindo a melhoria das condições do patrimônio socioambiental.

Essa concepção é fundamental para que possamos refletir sobre novas propostas e pensar a forma que está sendo conduzidos os processos educativos pois a "educação remete-nos a um conjunto de situações, de práticas, de políticas ligadas à educação no sentido amplo do termo".
(CHARLOT, 2006, p. 01).

Nesse sentido, a mediação entre sociedade e estado em busca de melhorias e efetivação do conjunto das políticas educacionais continua sendo uma necessidade tendo em vista a consolidação da Educação Ambiental. É de suma importância rever seus objetivos, avaliar os recursos financeiros e os instrumentos de gestão para a educação, verificando se estão sendo suficientes e adequados aos seus propósitos.

Com intervenção a participação efetiva da sociedade devemos retomar o controle social e planejar ações sistemáticas para que se possa aprender/compreender de fato como as políticas educacionais estão sendo desenvolvidas independente do que pensam os gestores formais dentro dos seus gabinetes. Queremos ampliar o conceito de gestores para abarcar os diferentes segmentos sociais.

Para tanto, se faz presente neste sentido, a participação mais próxima dos educadores na tomada de decisão para a construção e desenvolvimento dos processos educativos. Charlot (2006, p. 02) nos apresenta que "as ciências da educação possuem uma realidade institucional, administrativa, organizacional, mas não tem existência epistemológica específica". E neste sentido, supõe que, os processos educativos em cada localidade são realidades particularizadas sendo que, mesmo tendo efetivação e desenvolvimento com base no prescrito nas políticas, ainda assim, se faz necessário a intervenção social para que transpareça a valorização do processo de participação no controle social, assumindo, dessa forma, o papel do protagonismo de suas ações.

Ressalta Charlot (2006, p. 02) que o essencial é transgredir barreiras que apontam para "o problema fundamental que é, precisamente, passar do Eu Empírico ao Eu Epistêmico, ou seja, do indivíduo intelectualmente mobilizado, ou seja, o indivíduo preso no movimento da vida."

Apesar disso, permitir compreender como se dá o contexto e a organização dos trabalhos escolares que envolvem as políticas de educação com o objetivo de aprimorar a participação conjunta, cuidando, entretanto, da evolução individual e da produtividade para a melhoria educacional. 
Tomando como ponto de partida a perspectiva individual/coletiva e a participação nas ações iniciadas no local para depois expandir ao global. Essa a essência de nossas proposições neste artigo que julgamos fundamentais pois são esses os aspectos relevantes daquilo que consideramos emblemático no que convencionou-se chamar de "políticas efetivadas" e não somente "políticas formuladas".

\section{Conclusão}

Ao analisar alguns pressupostos legais das políticas públicas que rege a vida das pessoas, desvelamos lacunas que procuramos apontar para sua melhoria e efetivação.

Desse modo, podemos nos espantar com o que nos apresenta a Lei $n^{\circ} 9.795$, uma vez que a sociedade civil composta por indivíduos comuns são citados como coparticipantes na elaboração das leis, mas não podem, ou não estão efetivamente podendo, escrever seus anseios sendo protagonistas nas ações que visam a melhoria da qualidade de vida propondo e executando projetos e programas que visam a despoluição de córregos a céu aberto, a gestão dos lixões para transformá-los em aterro sanitário e o controle das inundações que vivenciam dia a dia. A Educação Ambiental como processo político e educativo poderá incentivar a fiscalização das políticas por meio da documentação e divulgação das ações individuais/coletivas que levem à participação na tomada de decisões tanto para a promulgação como para a efetivação de leis, programas e projetos do interesse da coletividade.

As posições desenvolvidas pelos governos com na elaboração de leis, programas e projetos são de forma inicial o que assegura a disseminação da informação para com os processos educativos. Mas, contido em lei está a premissa de que para a efetivação das políticas publicas a sociedade deve conhecer, se informar, e inteirar-se, sobre o que rege as leis nacionais estaduais e principalmente municipais. Esse é o ponto de partida de forma a ressignificação do conhecimento sobre as leis que somado ao saber popular e a cultura de participação podem resultar na tão almejada melhoria da qualidade de vida.
A sociedade também já está tomando para si atitudes e promovendo campanhas de conscientização para a participação nas políticas públicas principalmente nas questões educativas e ambientais. A mídia tem sido utilizada para a disseminação de informações, acerca de várias temáticas de conscientização sobre a alimentação saudável, saúde e preservação ambiental destacando o que se discute no âmbito federal e estadual sobre as políticas educacionais.

Assim, esperamos que as informações e os conhecimentos adquiridos transformem costumes que levam à passividade em novas atitudes que provoquem nos programas e projetos as mudanças ampliando a participação de pessoas sensíveis às questões sociais e ambientais emprestando novos significados aos processos educativos presentes nas diferentes políticas sociais que conferem à contemporaneidade essa abertura para novas esperanças de resgate de dívidas antigas que dizem respeito ao meio ambiente, saúde e qualidade de vida.

\section{Referências}

ANTUNES, C. Jogos para Estimulação

das BAHIA. SECRETARIA DO MEIO

AMBIENTE. Lei 12.056/11, DE 07 DE

JANEIRO DE 2011. Política Estadual de

Educação Ambiental. 2012. Acessado em: http:// www.meioambiente.ba.gov.br/arquivos/File/ Publicacoes/Livros/PoliticaEducacaoAmbiental. pdf> Data de acesso: 29/03/2018.

BRASIL. CASA CIVIL. LEI No 9.795, DE 27 DE ABRIL DE 1999. Política Nacional de

Educação Ambiental Acessado em: http:// www.planalto.gov.br/ccivil_03/leis/19795.htm >> Data de acesso:29/03/2018.

CARVALHO, I. 1 C. M. e SAMPAIO, G.

Hannah Arendt: natureza, história e ação humana. In:_ Pensar o Ambiente: bases filosóficas para a Educação Ambiental. / Organização: Isabel Cristina Moura de Carvalho, Mauro Grün e Rachel Trajber. Brasília: Ministério da Educação, Secretaria 
de Educação Continuada, Alfabetização e Diversidade, UNESCO, 2006.

Cadernos do Cedes/Centro de Estudos Educação Sociedade-vol. 1n1 (1980) São Paulo. Cortez, Campinas, Cedes, 1980.

\section{CHARLOT, B. A pesquisa educacional} entre conhecimentos, políticas e práticas: especificidades e desafios de uma área de saber. Revista Brasileira de Educação v. 11 n. 31 jan./ abr. 2006.

\section{GRÜN, M. D. Historicidade e Educação} Ambiental. In: Pensar o Ambiente: bases filosóficas para a Educação Ambiental. / Organização: Isabel Cristina Moura de Carvalho, Mauro Grün e Rachel Trajber. Brasília: Ministério da Educação, Secretaria de Educação Continuada, Alfabetização e Diversidade, UNESCO, 2006.

\section{MUTIM, A. L. B. Uma práxis Educativa} Transdisciplinar em Educação Ambiental, In: Cadernos CEDES, 29, 1 edição, 1993, Papirus, Rio de Janeiro, p. $63-68$.

NOVAES, I. L,; CARNEIRO, B. P. B.. Enlaces entre subjetividade, percepção e produção de sentido na gestão escolar. In:

Revista da FAEEBA: educação e contemporaneidade / Universidade do Estado da Bahia, Departamento de Educação I - v. 1, n. 1 (jan./jun.,1992) - Salvador: UNEB, 1992.

PEloggia, A. U. G.; ORTEGA, A. M. A Teoria do Conhecimento de Álvaro Vieira Pinto: uma perspectiva onto-gnosiológica. Acessado em: http://www.necso.ufrj.br/ vi_esocite_br-tecsoc/gts/gt-01-alex_ubiratan goossens_pelogia_e_any_marise_ortega.pdf. Data de acesso: $2 \overline{4} / 07 / 18$.

\section{SOUZA, C. "Estado da Arte" da Área de}

Políticas Públicas: Conceitos e Principais Tipologias. XXVII Encontro Anual da Associação Nacional de Pós-Graduação e Pesquisa em Ciências Sociais (ANPOCS) GT:
Políticas Públicas Caxambu, MG. 21-25 de outubro de 2003.

TOZONI-REIS, M. F. C. Educação Ambiental: natureza, razão e história. 2 ed. Ver. Campinas. Autores Associados, 2008.

\section{Sobre os autores}

Simone Teles da Silva Santo é mestranda do programa de Pós-graduação em educação e contemporaneidade - PPGEduC e Integrante do Grupo de Estudos e Pesquisa Educação Ambiental, Políticas Públicas e Gestão Social dos Territórios - GEPET da Universidade do Estado da Bahia - UNEB/Campus I Salvador. Especialista em Inovação Social com ênfase em Economia Solidária e Agroecologia pelo Instituto Federal- IFBaiano/Campus Bom Jesus da Lapa. Licenciada em Pedagogia pela Universidade do Estado da Bahia-UNEB/Campus XVII Bom Jesus da Lapa. E-mail: Simone.teles.silva@ gmail.com ORCID 0000-0002-7016-1163

Avelar Luíz Bastos Mutim é Professor Titular do Pós-Graduação em Educação e Contemporaneidade/PPGEduC- Mestrado e Doutorado - Universidade do Estado da Bahia/ UNEB. Líder do Grupo de Pesquisa "Educação Ambiental, Políticas Públicas e Gestão Social dos Territórios-GEPET. E-mail: amutim@uneb. br Orcid: 0000-0002-8032-9679 